\title{
Neurocognitive and neuroanatomic changes after off-pump versus on-pump coronary artery bypass grafting: Long-term follow-up of a randomized trial
}

\author{
John D. Puskas, MD, ${ }^{a}$ Anthony Stringer, PhD, ${ }^{\mathrm{b}}$ Scott N. Hwang, MD, PhD, ${ }^{\mathrm{c}}$ Brannon Hatfield, MD, ${ }^{c}$ \\ A. Shannon Smith, RN, ${ }^{a}$ Patrick D. Kilgo, MS, ${ }^{\text {ad }}$ and Willis H. Williams, MD ${ }^{\mathrm{a}}$
}

Objective: It is unknown whether avoidance of cardiopulmonary bypass during coronary artery bypass grafting affects cerebral injury or long-term neuropsychological function.

\begin{abstract}
Methods: Two hundred unselected patients were randomized to off-pump coronary artery bypass or on-pump coronary artery bypass grafting between March 2000 and August 2001. One hundred sixty-eight patients had early postoperative brain magnetic resonance imaging. Eighty-seven returned after a mean of 7.5 years of follow-up; 67 had repeat magnetic resonance imaging, and 76 had neuropsychological testing.
\end{abstract}

\begin{abstract}
Results: There were 26 deaths among patients undergoing off-pump coronary artery bypass and 31 among patients undergoing cardiopulmonary bypass as of March 2009. Seventy-six patients (41 undergoing cardiopulmonary bypass and 35 undergoing off-pump coronary artery bypass) had neuropsychological testing at late follow-up. Groups were similar in age, sex, depression, and IQ. Patients undergoing off-pump coronary artery bypass showed better attention, performing better at tracking and mentally manipulating information $(P=.011)$. Patients undergoing off-pump coronary artery bypass demonstrated better cognitive reasoning and made fewer errors in reasoning $(P=.05)$; they also showed a trend toward better verbal learning $(P=.064)$. There were no domains in which patients undergoing cardiopulmonary bypass outperformed those undergoing off-pump coronary artery bypass. Early magnetic resonance imaging in 168 patients showed no significant differences between groups in temporal or frontal lobe atrophy, subcortical white matter lesions, or acute infarctions. There were no significant differences between groups in atrophy over time or new subcortical white matter lesions or infarctions. Acute perioperative cerebral infarctions were more common and atrophy more progressive during follow-up among diabetic than nondiabetic patients.
\end{abstract}

Conclusions: After a mean of 7.5 years of follow-up, patients undergoing off-pump coronary artery bypass performed better than those undergoing cardiopulmonary bypass in several neuropsychological domains; these differences were small and of uncertain clinical importance. Early brain magnetic resonance imaging showed no significant differences in acute cerebral infarctions between the off-pump coronary artery bypass and cardiopulmonary bypass groups. (J Thorac Cardiovasc Surg 2011;141:1116-27)

In an effort to avoid morbidity attributed to cardiopulmonary bypass $(\mathrm{CPB})$, aortic cannulation/clamping, hypothermic cardioplegic arrest, and systemic hemodilution, off-pump coronary artery bypass (OPCAB) techniques were refined and popularized in the 1990s. ${ }^{1,2}$ Despite

From the Clinical Research Unit, ${ }^{\text {a }}$ Division of Cardiothoracic Surgery, and the Departments of Rehabilitation Medicine ${ }^{\mathrm{b}}$ and Radiology, ${ }^{\mathrm{c}}$ Emory University School of Medicine, and the Rollins School of Public Health, ${ }^{\mathrm{d}}$ Emory University, Atlanta, $\mathrm{Ga}$.

Disclosures: Authors have nothing to disclose with regard to commercial support. Read at the 90th Annual Meeting of The American Association for Thoracic Surgery, Toronto, Ontario, Canada, May 1-5, 2010.

Received for publication May 4, 2010; revisions received Dec 14, 2010; accepted for publication Jan 7, 2011; available ahead of print Feb 21, 2011.

Address for reprints: John D. Puskas, MD, Clinical Research Unit and Division of Cardiothoracic Surgery, Emory University, Department of Cardiac Surgery, Emory University Hospital Midtown, 550 Peachtree St, 6th Floor Medical Office Tower, Atlanta, GA 30342 (E-mail: john.puskas@emoryhealthcare.org).

$0022-5223 / \$ 36.00$

Copyright (c) 2011 by The American Association for Thoracic Surgery doi:10.1016/j.jtcvs.2011.01.013 reports of improved outcomes with OPCAB from numerous centers ${ }^{3,4}$ and from the Society of Thoracic Surgeons (STS) National Cardiac Database ${ }^{5}$ and the US Veterans Administration database, ${ }^{6}$ adoption of OPCAB plateaued at approximately $20 \%$ in 2004 and has not changed significantly since that time. ${ }^{7}$ This might be due in part to the technically challenging nature of OPCAB and in part due to the lack of compelling reductions in major adverse cardiac events (death, stroke, and myocardial infarction) among the low-risk patients enrolled in small, underpowered randomized controlled trials comparing OPCAB with conventional CABG techniques. ${ }^{8,9}$

One of the strong motivations to explore and adopt OPCAB techniques has been the hope that avoidance of $\mathrm{CPB}$ and reduced aortic manipulation would be associated with reduced risk of perioperative stroke and neurocognitive decline associated with coronary artery bypass surgery. ${ }^{10}$ Typically enrolling low-risk patients, randomized trials to date have been underpowered to detect a difference in 

Abbreviations and Acronyms
$\begin{array}{ll}\mathrm{CPB} & =\text { cardiopulmonary bypass } \\ \mathrm{CSF} & =\text { cerebrospinal fluid }\end{array}$
FLAIR = fluid attenuated inversion recovery
MRI = magnetic resonance imaging
OPCAB $=$ off-pump coronary artery bypass
RAVLT $=$ Rey Auditory Verbal Learning Test
ROI $=$ region of interest
SMART $=$ Surgical Management of Arterial
Revascularization Therapies
STS $=$ Society of Thoracic Surgeons

perioperative stroke, an infrequently occurring end point. ${ }^{9,11-15}$ Nonetheless, risk-adjusted retrospective reviews of numerous large clinical databases have repeatedly demonstrated a clinically and statistically significant reduction in perioperative stroke for patients undergoing OPCAB compared with conventional $\mathrm{CABG}$ during $\mathrm{CPB}$. $5,6,16,17$ The early studies among these patients were legitimately criticized because of their inability to account for intraoperative conversion of patients from OPCAB to CPB to report an intent-to-treat comparison. This potential source of bias was addressed by the introduction of a data field in the STS National Cardiac Database to report intraoperative conversion and subsequently by the first intent-to-treat analysis of the STS database, which confirmed an adjusted odds ratio for stroke in patients undergoing OPCAB of $0.65(P<.001){ }^{16}$

Although it seems logical that elimination of CPB and reduction in aortic manipulation should reduce the risk of embolic and ischemic stroke, ${ }^{18}$ it must also be acknowledged that the specific technique for performing (or avoiding) proximal anastomoses on the ascending aorta (including single, double, or no aortic clamp) can have a significant effect on stroke risk, especially in patients with atherosclerosis of the ascending aorta, independent of the use or avoidance of CPB during surgical coronary revascularization. ${ }^{19}$

Whether CABG causes neurocognitive decline $e^{20-22}$ is contested, and several studies have reported similar change from baseline neurocognitive function in risk-matched ${ }^{23}$ or randomized $^{24}$ patients undergoing CABG versus percutaneous coronary intervention or $\mathrm{CABG}$ versus noncardiac surgical procedures. ${ }^{25}$ Measures of neurocognitive or neuropsychological function are inherently imprecise and prone to a variety of systemic biases and confounders. Moreover, there is no general agreement on which of the many available tests are most appropriate, ${ }^{26}$ what would constitute a clinically significant decline, ${ }^{27}$ or even how to best perform statistical comparisons of test scores across multiple neuropsychological domains. ${ }^{28}$ Perhaps as a result of this methodological imprecision, single-center prospective studies have reported "significant" decline relative to that seen in control subjects in neuropsychological performance ranging from zero percent ${ }^{23}$ to $53 \%{ }^{20}$ of patients after conventional CABG during CPB.

Magnetic resonance imaging (MRI), especially with diffusion-weighted techniques, has been the preferred imaging modality to demonstrate acute cerebral emboli. Nonetheless, the resolution of presently available scanners is such that defects smaller than $1 \mathrm{~mm}$ are not detectable. Moreover, the correlation between detection of new brain lesions on MRI scanning and the appearance of new decline in neurocognitive function has been disappointingly weak in at least 1 previous small clinical series. ${ }^{29}$

The Surgical Management of Arterial Revascularization Therapies (SMART) trial was conceived to rigorously compare completeness of revascularization, clinical outcomes, and resource use in unselected patients referred for elective primary $\mathrm{CABG}$ randomly assigned to undergo OPCAB or conventional $\mathrm{CABG}$ during $\mathrm{CPB}$. Similar graft patency was demonstrated between groups by means of coronary angiographic analysis before hospital discharge and at the 1-year follow-up and by means of computed tomographic angiographic analysis at a mean of 7.5 years of followup. $^{13,30,31}$ The principal secondary end points of the SMART trial were neuroanatomic and neurocognitive outcomes, as measured by using early and late diffusionweighted brain MRI and neuropsychological testing at late follow-up. These results are the subject of this report.

\section{MATERIALS AND METHODS}

Between March 2000 and August 2001, 297 unselected patients with multivessel coronary artery disease were approached for voluntary enrollment in the SMART trial. Two hundred of these 297 patients were randomly assigned to undergo off-pump or on-pump coronary artery bypass grafting by a single surgeon (J.D.P.). A single crossclamp was used in the CPB group; partial occlusion clamping of the ascending aorta was used for proximal anastomoses in the OPCAB group, when intraoperative epiaortic ultrasound scanning of the ascending aorta revealed less than grade 3 atherosclerosis. The sample size for the SMART trial was chosen for the ability to detect a $5 \%$ absolute difference between groups in the primary end point of graft patency.

After a mean of 7.5 years (range, 6.8-8.4 years), 87 of the original participants volunteered to return for late follow-up. As of March 30, 2009, there were 26 deaths from all causes among patients undergoing OPCAB and 31 among patients undergoing CPB since initial enrollment. Reasons for loss of patients to follow-up are listed in the consort flow diagram (Figure 1).

\section{Neuropsychological Testing}

Of the 87patients who returned for late follow-up, 76 (41 undergoing $\mathrm{CPB}$ and 35 undergoing $\mathrm{OPCAB}$ ) underwent a focused battery of neuropsychological tests to determine whether the surgical groups differed with respect to cognitive function. The trained and certified neuropsychological test administrators were blinded to treatment assignment. Table 1 lists the neuropsychological test by domain. Each test is briefly described below.

\section{Attention.}

A. Wechsler Memory Scale-3 Digit and Spatial Span: Patients listened to sequences of digits and viewed sequences of spatial positions, 
Flow Diagram of Surgical Management of Arterial Revascularization Therapies (SMART) Tria

\begin{tabular}{|c|c|}
\hline \multicolumn{2}{|c|}{ 200/297 Screened Patients Randomized (2000-2001) } \\
\hline $\begin{array}{l}100 \text { Assigned to OPCAB } \\
2 \text { Withdrawn due to Mitral Valve Disease } \\
1 \text { Crossed over to CPB }\end{array}$ & $\begin{array}{l}100 \text { Assigned to CABG with CPB } \\
1 \text { Withdrawn due to Mitral Valve Disease } \\
3 \text { Crossed over to OPCAB }\end{array}$ \\
\hline $\begin{array}{l}93 \text { Completed post-op in-hospital } \\
\text { Angiogram }\end{array}$ & $\begin{array}{l}91 \text { Completed post-op in-hospital } \\
\text { Angiogram }\end{array}$ \\
\hline $\begin{array}{l}1 \text { Died within } 30 \mathrm{~d} \\
3 \text { Died between } 30 \mathrm{~d}-1 \mathrm{yr} \\
94 \text { Alive at } 1 \mathrm{yr}\end{array}$ & $\begin{array}{l}2 \text { Died within } 30 \mathrm{~d} \\
2 \text { Died between } 30 \mathrm{~d}-1 \mathrm{yr} \\
95 \text { Alive at } 1 \mathrm{yr}\end{array}$ \\
\hline 76/94 Completed 1 yr Angiogram & 77/95 Completed 1 yr Angiogram \\
\hline $\begin{array}{l}22 \text { Died Between } 1 \mathrm{yr}-8 \mathrm{yrs} \\
72 \text { Alive at } 8 \mathrm{yrs}\end{array}$ & $\begin{array}{l}27 \text { Died between } 1 \mathrm{yr}-8 \mathrm{yrs} \\
68 \text { Alive at } 8 \mathrm{yrs}\end{array}$ \\
\hline $\begin{array}{l}43 / 72(60 \%) \text { OPCAB pts had F/U at } 8 \text { yrs } \\
30 \text { had CTA } \\
34 \text { had PET } \\
\text { (29 had both CTA and PET) } \\
35 \text { had NP Testing }\end{array}$ & $\begin{array}{l}\text { 44/68 }(65 \%) \text { CPB pts had } 8 \text { yr F/U } \\
37 \text { had CTA } \\
40 \text { had PET } \\
\text { ( } 37 \text { had both CTA and PET) } \\
41 \text { had NP Testing }\end{array}$ \\
\hline
\end{tabular}

FIGURE 1. Consort flow diagram of SMART trial. $O P C A B$, Off-pump coronary artery bypass; $C A B G$, coronary artery bypass grafting; $C P B$, cardiopulmonary bypass; $M R I$, magnetic resonance imaging; $F / U$, follow-up; $C T A$, computed tomographic angiography; PET, positron emission tomography; $N P$, neuropsychological.

both of which they were required to reproduce in forward and reverse order. Scores are numbers of digits or spatial positions correctly reported in forward and backward sequence.

II. Memory function

A. Rey Auditory Verbal Learning Test (RAVLT): The RAVLT uses a verbally presented list learning task to measure immediate verbal memory span, the ability to learn from repetition, and retention after a delay and an interpolated task. Scores are numbers or items correct on the last of the 5 learning trials and the delayed recall trial.

B. Brief Visuospatial Memory Test-Revised: Patients attempt to draw a series of designs from memory over 3 learning trials and again after a delay. The Brief Visuospatial Memory Test-Revised measures immediate visual memory span, learning of nonverbal information, and visual retention after a delay. Scores are the number of designs recalled on the last of the 3 learning trials and the delayed recall trial.

III. Executive and intellectual functions

A. Wechsler Abbreviated Scale of Intelligence: The Wechsler Abbreviated Scale of Intelligence provides an estimate of full-scale IQ based on 2 subtests measuring vocabulary and nonverbal reasoning.

B. Booklet Category Test (Short Form): On each trial of this untimed test, patients viewed a series of 4 pictured objects or designs to determine a target principle for categorizing the stimuli. This test

TABLE 1. Neuropsychological battery

I. Attention
A. Wechsler Memory Scale-3 Digit and Spatial Span
II. Memory
A. Rey Auditory Verbal Learning Test
B. Brief Visuospatial Memory Test-Revised
III. Executive and intellectual functions
A. Wechsler Abbreviated Scale of Intelligence (2 subtest)
B. Booklet Category Test (short form)
IV. Mood
A. Beck Depression Inventory-2

assesses categorical reasoning, problem solving, and the ability to IV. Mood

learn from experience. The score reports the total number of errors.

A. Beck Depression Inventory: A 21-item inventory providing a quantitative assessment of the intensity of functional depressive symptomatology. It has been normed for adults, validated in the literature, and widely used for research into depression in surgical and nonsurgical disease states.

\section{Brain MRI Scanning and Image Interpretation}

Early MRI of the brain was performed during the index hospitalization on a Philips Gyroscan ACS-NT 1.5 T scanner. Late MRI images at longterm follow-up were acquired on a GE Healthcare Signa HDx 1.5T MR scanner. The axial T1-weighted, axial T2-weighted, axial fluid attenuated inversion recovery (FLAIR), and axial diffusion-weighted images were interpreted by a board-certified neuroradiologist.

Cerebral white matter lesions are identified by areas of abnormal hyperintensity in the T2-weighted or FLAIR images, which represent parenchymal injury of predominately indeterminate acuity or chronicity. These lesions are nonspecific and can be secondary to almost any pathologic process, including ischemia, inflammation, infection, or neoplasm. Given the relatively advanced age of the patients enrolled in this study, these lesions most likely represent chronic microvascular ischemic changes, which tend to increase in prevalence with age and are associated with common cardiovascular risk factors, such as hypertension. Diffusion abnormalities, defined as areas of restricted diffusion, are also nonspecific but most commonly associated with acute or subacute infarction.

White matter lesions and areas of diffusion abnormalities were interpreted according to a scoring system modified from the work by Scheltens and colleagues ${ }^{32}$ :

1. Temporal lobe atrophy and frontal lobe atrophy were each subjectively graded on a scale from 0 (normal) to 4 (severe).

2. Hyperintense white matter lesions in either the T2-weighted or FLAIR images were graded from 0 (normal) to 6 (severe), according to the ordinal scale shown in Table 2.

3. Lesions with diffusion abnormality (acute or subacute infarctions) were graded by using the same scale.

The late follow-up MRI images were scored by using the same scales and supplemented with an additional score for periventricular lesions. For purposes of scoring, periventricular lesions were defined as those in contact with the ventricles. The thickness of the lesions was measured along the lateral ventricles. Three separate scores were given for lesions adjacent to the frontal horns of the lateral ventricles (anterior), adjacent to the bodies (mid), and adjacent to the trigones (posterior; Table 3 ).

An additional quantitative image analysis was performed to compute regional cerebrospinal fluid (CSF) volumes to quantitatively assess brain parenchymal volume loss (atrophy). The images of the multiple pulse sequences were spatially registered with each other, and a region of interest (ROI) was manually drawn in the white matter of the corpus callosum

TABLE 2. Ordinal scoring for white matter lesions

\begin{tabular}{|c|c|c|}
\hline Score & Lesion size & Lesion no. \\
\hline \multicolumn{3}{|c|}{0 (normal) } \\
\hline 1 & All lesions are $<4 \mathrm{~mm}$ & $<6$ \\
\hline 2 & All lesions are $<4 \mathrm{~mm}$ & $\geq 6$ \\
\hline 3 & The largest lesion measures between 4 and $10 \mathrm{~mm}$ & $<6$ \\
\hline 4 & The largest lesion measures between 4 and $10 \mathrm{~mm}$ & $\geq 6$ \\
\hline 5 & At least 1 lesion is $>10 \mathrm{~mm}$ & \\
\hline 6 & $\begin{array}{l}\text { Severe confluent parenchymal signal abnormality } \\
\text { or transcortical territorial infarction is present }\end{array}$ & \\
\hline
\end{tabular}


TABLE 3. Scoring for periventricular lesions

\begin{tabular}{ll}
\hline Score & Lesion thickness \\
\hline 0 & Normal \\
1 & $\leq 5 \mathrm{~mm}$ \\
2 & $>5 \mathrm{~mm}$ but $\leq 10 \mathrm{~mm}$ \\
3 & $>10 \mathrm{~mm}$ \\
\hline
\end{tabular}

(splenium, genu, or both) of each patient. Each image was then normalized with the average white matter intensity computed from the ROI. Other ROIs were drawn in the gray matter (thalamus) and CSF (lateral ventricles) to obtain characteristic signal intensities. The "distance" $d$ for each voxel was then computed relative to the characteristic signal intensities. Analogous equations defined the distances for gray matter $\left(\mathrm{d}_{\mathrm{GM}}\right)$ and white matter $\left(d_{W M}\right)$. Segmented images were manually checked and corrected, such as excluding the voxels representing fluid in the orbital globes. The volume of CSF was then computed in groups of compartments corresponding to the anterior frontal, frontal periventricular, anterolateral temporal, medial temporal, perisylvian, and peritrigonal regions of the brain in a manner similar to the work by Arimura et $\mathrm{al}^{33}$ (Figure 2).

Brain MRI scans were scored on ordinal scales with respect to diffusionweighted lesions, T2, temporal lobe atrophy, and frontal lobe atrophy. Comparisons of OPCAB versus CABG during CPB with respect to these scales were made for both early MRI studies $(n=83$ and $n=85$, respectively) and late follow-up MRI ( $n=35$ and $n=32$, respectively). Furthermore, for patients who had scans at both time points $(n=27$ and $n=32$, respectively), the change in ordinal status was compared across groups to see whether one group experienced statistically different changes over time. All analyses of ordinal scales were made by using nonparametric Wilcoxon tests.

The correlations between the neuropsychological test results and the MRI findings were estimated by using the Spearman rank coefficient (the nonparametric statistic was used because of the ordinal nature of the MRI measurements). The previously described neuropsychological test results were analyzed for correlation with MRI findings at both baseline and up to the 8-year follow-up. For patients who had MRI performed at both time points, the neuroanatomic changes from baseline to follow-up were correlated with neuropsychological test results. Furthermore, neuropsychological test results were examined for correlation with CSF volumes measured in 6 brain regions: anterior frontal lobes, frontal periventricular, anterolateral temporal, medial temporal, perisylvian, and peritrigonal.

\section{Statistical Analysis}

To address concerns about selection bias in the present follow-up study, $\chi^{2}$ and $t$ tests were performed to determine whether the means of clinical risk factors of the returning group of SMART patients (1) differed according to their original type of operation (OPCAB or conventional CABG) and (2) differed from the original cohort in general. Furthermore, common confounders of cognitive effects, including age, sex, and IQ, were examined for differences across groups. All analyses were performed with SAS Version 9.2 software (SAS Institute, Inc, Cary, NC). All tests were evaluated at the .05 significance level. No adjustments for multiple tests were performed.

\section{RESULTS}

Among the 41 patients undergoing $\mathrm{CPB}$ and 35 patients undergoing $\mathrm{OPCAB}$ tested for cognitive function, the mean age was 66.7 years (range, $38-90$ years). Patients undergoing OPCAB (mean, 64.9 years; range, 38-90 years) were younger than patients undergoing CPB (mean, 68.3 years; range, 52-89 years), but the difference was not statistically different $(P=.14)$. Nine $(22.0 \%)$ patients undergo-
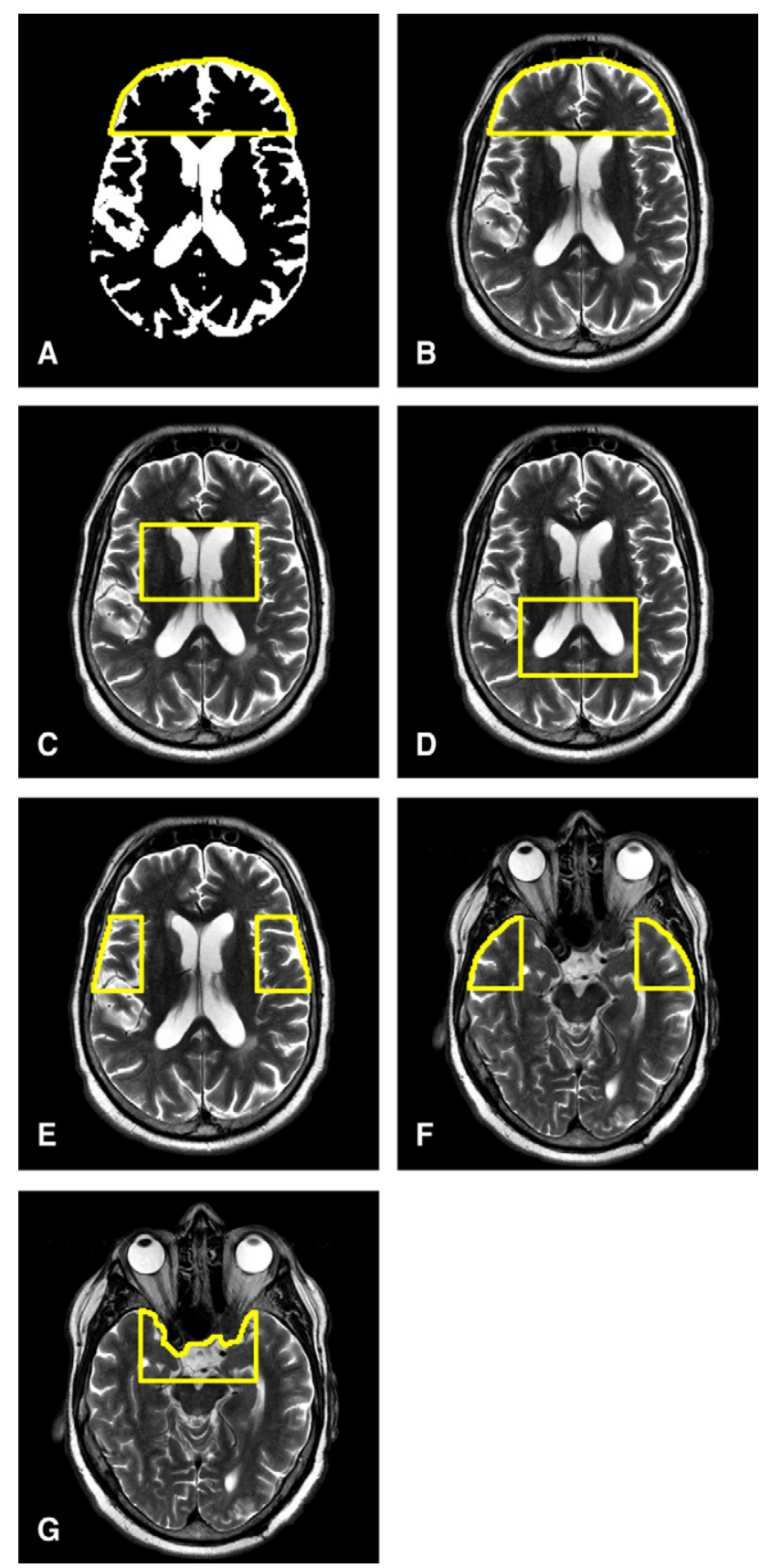

FIGURE 2. Cross-sections of the regions of analysis in the brain. A, Segmented imaged showing cerebrospinal fluid voxels in white. The anterior frontal region of interest is outlined. Cross-sections through the regions of interest superimposed on T2-weighted images: B, anterior frontal; C, anterior periventricular; $\mathrm{D}$, peritrigonal; E, perisylvian; $\mathrm{F}$, anterolateral temporal; and $\mathrm{G}$, anteromedial temporal.

ing $\mathrm{CPB}$ and $8(22.9 \%)$ patients undergoing $\mathrm{OPCAB}$ were female $(P=.92)$. The groups were also similar with respect to all preoperative clinical characteristics (Table 4). The patients who returned for follow-up were not significantly different either between groups at follow-up or compared with the original groups at the time of randomization. 
TABLE 4. Comparison of preoperative characteristics of the original patient cohort and the subset who underwent follow-up NP study

\begin{tabular}{|c|c|c|c|c|c|c|}
\hline \multirow[b]{2}{*}{ Characteristic } & \multicolumn{3}{|c|}{ Original SMART study $(n=197)$} & \multicolumn{3}{|c|}{ SMART NP study follow-up $(n=76)$} \\
\hline & $\begin{array}{l}\text { CABG during } \\
\text { CPB }(n=99)\end{array}$ & $\begin{array}{l}\text { OPCAB } \\
(\mathbf{n}=\mathbf{9 8}) \\
\end{array}$ & $P$ value & $\begin{array}{l}\text { CABG during } \\
\text { CPB }(n=41)\end{array}$ & $\begin{array}{l}\text { OPCAB } \\
(\mathbf{n}=\mathbf{3 5}) \\
\end{array}$ & $\begin{array}{c}P \\
\text { value }\end{array}$ \\
\hline Age at enrollment (mean $\pm \mathrm{SD})$ & $62.5(9.5)$ & $62.1(11.1)$ & 0.82 & $60.8(8.8)$ & $57.5(10.8)$ & .14 \\
\hline Female sex $(\%)$ & $23(23)$ & $22(22)$ & 0.90 & $9(22.0)$ & $8(22.9)$ & .92 \\
\hline \multicolumn{7}{|l|}{ Baseline ejection fraction $(\%)$} \\
\hline$>55 \%$ & $49(51)$ & $52(54)$ & 0.78 & $21(52.5)$ & $21(60.0)$ & .86 \\
\hline $45 \%-54 \%$ & $22(23)$ & $21(22)$ & & $10(25.0)$ & $8(22.9)$ & \\
\hline $35 \%-44 \%$ & $11(11)$ & $15(15)$ & & $6(15.0)$ & $4(11.4)$ & \\
\hline $25 \%-34 \%$ & $7(7)$ & $5(5)$ & & $1(2.5)$ & $0(0.0)$ & \\
\hline$<25 \%$ & $6(6)$ & $4(4)$ & & $2(5.0)$ & $2(5.7)$ & \\
\hline Previous MI (\%) & $31(31)$ & $34(35)$ & 0.61 & $13(31.7)$ & $12(34.4)$ & .81 \\
\hline Previous CVA (\%) & $9(9)$ & $1(1)$ & 0.01 & $3(7.3)$ & $0(0.0)$ & .10 \\
\hline Previous TIA ( $\%$ ) & $1(1)$ & $3(3)$ & 0.31 & $1(2.4)$ & $1(2.9)$ & .91 \\
\hline COPD $(\%)$ & $8(8)$ & $10(10)$ & 0.61 & $2(4.9)$ & $0(0.0)$ & .19 \\
\hline Current smoker $(\%)$ & $31(31)$ & $27(28)$ & 0.56 & $10(24.4)$ & $8(22.9)$ & .88 \\
\hline Diabetes $(\%)$ & $33(33)$ & $32(33)$ & 0.96 & $17(41.5)$ & $10(28.6)$ & .24 \\
\hline Diet & $21(21)$ & $24(24)$ & 0.58 & $10(24.4)$ & $6(17.1)$ & .44 \\
\hline Insulin & $10(10)$ & $9(9)$ & 0.83 & $6(14.6)$ & $5(14.3)$ & .97 \\
\hline Oral & $24(24)$ & $22(22)$ & 0.77 & $11(26.8)$ & $5(14.3)$ & .18 \\
\hline Hypertension (\%) & $61(62)$ & $64(65)$ & 0.59 & $28(68.3)$ & $22(62.9)$ & .62 \\
\hline Angioplasty (\%) & $15(15)$ & $23(23)$ & 0.14 & $9(22.0)$ & $8(22.9)$ & .92 \\
\hline Stent $(\%)$ & $6(6)$ & $9(9)$ & 0.41 & $4(9.8)$ & $5(14.3)$ & .54 \\
\hline Hypercholesterolemia (\%) & $47(47)$ & $48(49)$ & 0.83 & $21(51.2)$ & $16(45.7)$ & .63 \\
\hline PVD (\%) & $10(10)$ & $13(13)$ & 0.49 & $3(7.3)$ & $2(5.7)$ & .78 \\
\hline Renal failure (\%) & $4(4)$ & $2(2)$ & 0.41 & $0(0.0)$ & $0(0.0)$ & 1.0 \\
\hline Dialysis dependent (\%) & $1(1)$ & $1(1)$ & 0.99 & $0(0.0)$ & $0(0.0)$ & 1.0 \\
\hline NYHA class III or IV $(\%)$ & $1(1)$ & $2(2)$ & 0.38 & $1(2.4)$ & $0(0.0)$ & .62 \\
\hline CCS class III or IV $(\%)$ & $12(12)$ & $24(25)$ & 0.12 & $5(12.2)$ & $10(28.6)$ & .22 \\
\hline
\end{tabular}

$N P$, Neuropsychological; SMART, Surgical Management of Arterial Revascularization Therapies; $C A B G$, coronary artery bypass grafting; $C P B$, cardiopulmonary bypass; $O P C A B$, off-pump coronary artery bypass; $S D$, standard deviation; $M I$, myocardial infarction; $C V A$, cerebrovascular accident; TIA, transient ischemic attack; COPD, chronic obstructive pulmonary disease; PVD, peripheral vascular disease; NYHA, New York Heart Association; CCS, Canadian Cardiovascular Society.

Furthermore, on full-scale testing, IQ was found to be statistically similar between the CPB and OPCAB groups $(96.2$ vs $101.4, P=.21$ ).

Table 5 summarizes the analyses of the neuropsychological test results, which were performed only once, at a mean of 7.5 years of follow-up. Statistically significant differences between groups were seen primarily on tests of executive function. Although the magnitudes of the differences are small, patients undergoing OPCAB obtained higher scores on Spatial Span Backward and made fewer errors on the Short Category Test. Patients undergoing OPCAB also tended to remember more items from the RAVLT by the final learning trial, although the difference between groups was not statistically significant. A comparison of neuropsychological function after $\mathrm{OPCAB}$ versus $\mathrm{CPB}$ among diabetic patients is presented in Table 6. In all 13 neuropsychological tests the mean performance score for patients with OPCAB was superior to that of patients with CPB. Perhaps because of the small diabetic sample size at follow-up (10 patients undergoing OPCAB vs 17 patients undergoing $\mathrm{CPB}$ ), none of these individual test scores were statistically significant.
Table 7, shows the findings of early MRI among 168 patients and late MRI among 67 patients. Early MRI in 168 patients showed no significant differences between surgical treatment groups in atrophy, subcortical white matter lesions, or acute infarctions. Among 59 patients who had both early and late MRI, there were no significant differences between surgical treatment groups with respect to atrophy over time or new subcortical white matter lesions or infarctions. Interestingly, there were significantly more diffusion-weighted abnormalities in subcortical white matter (new cerebral infarctions) among patients with diabetes than among patients without diabetes in both surgical treatment groups (Table 8) early after surgical intervention. Moreover, although baseline atrophy scores were similar for diabetic and nondiabetic patients early after surgical intervention, there was significantly greater cerebral atrophy at follow-up and a significantly greater increase in atrophy between baseline and follow-up among diabetic patients than among nondiabetic patients. However, there were statistically similar numbers of new diffusion-weighted abnormalities in subcortical white matter among diabetic patients who had CPB and those who had OPCAB. Atrophy over 7.5 
TABLE 5. Neuropsychological test comparison between surgical groups at a mean of 7.5 years of follow-up

\begin{tabular}{|c|c|c|c|c|}
\hline Domain & Variable & $\operatorname{CPB}(n=41)$ & OPCAB $(\mathbf{n}=35)$ & $P$ value \\
\hline Attention & Digit Span Forward & $6.07(1.19)$ & $6.34(1.39)$ & .37 \\
\hline Attention & Digit Span Backward & $4.15(1.15)$ & $4.57(1.44)$ & .16 \\
\hline Attention & Spatial Span Forward & $5.00(1.07)$ & $5.03(1.20)$ & .91 \\
\hline Attention & Spatial Span Backward & $4.39(1.0)$ & $5.03(1.12)$ & .011 \\
\hline Memory & RAVLT Trial 5 & $9.07(2.39)$ & $10.23(2.88)$ & .06 \\
\hline Memory & RAVLT Delayed Recall & $6.68(2.56)$ & $7.54(3.33)$ & .21 \\
\hline Memory & BVMT-R Trial 3 & $6.61(3.37)$ & $6.86(3.16)$ & .74 \\
\hline Memory & BVMT Delayed Recall & $5.98(3.04)$ & $6.40(3.26)$ & .56 \\
\hline Executive/Intellectual & WASI Full-Scale IQ & $96.2(17.7)$ & $101.4(18.0)$ & .21 \\
\hline Executive/Intellectual & WASI Vocabulary IQ & $9.4(3.5)$ & $10.3(3.4)$ & .27 \\
\hline Executive/Intellectual & WASI Matrix IQ & $8.9(4.1)$ & $10.0(3.8)$ & .22 \\
\hline Executive/Intellectual & Short Category Test Errors & $45.6(11.2)$ & $39.5(14.9)$ & .05 \\
\hline Mood & Beck Depression Inventory & $6.4(5.3)$ & $6.5(8.4)$ & .95 \\
\hline
\end{tabular}

Data are presented as means (standard deviations). $C P B$, Cardiopulmonary bypass; $O P C A B$, off-pump coronary artery bypass; $R A V L T$, Rey Auditory Verbal Learning Test; $B V M T-R$, Brief Visuospatial Memory Test-Revised; WASI, Wechsler Abbreviated Scale of Intelligence.

years of follow-up was also similar for diabetic patients who had CPB and those who had OPCAB (Table 9).

The first 4 rows of Table 10 show the correlation between baseline (early) brain MRI and neuropsychological test result at late follow-up. Correlational analyses were done specifically on neuropsychological tests for which a statistically significant difference (or trend toward a significant difference) in scores was found between the CPB and OP$\mathrm{CAB}$ groups. At baseline, these findings indicate that patients with greater degrees of frontal atrophy performed less well on the Wechsler Memory Scale Spatial Span Backwards score $(r=-0.29, P=.024)$ and the number of Short Category Test errors $(r=0.32, P=.012)$, again indicating that impaired cognitive test performance is associated with cerebral atrophy.

The middle 4 rows of Table 10 show correlation between brain MRI images at late follow-up and neuropsychological test results at late follow-up. At follow-up, significant associations were seen between temporal lobe atrophy and both the Wechsler Memory Score $(r=-0.27, P=.041)$ and the
RAVLT-5 $(r=-0.30, P=.021)$, indicating that increased atrophy does indeed result in diminished cognitive abilities. Similarly, frontal lobe atrophy was significantly related to the Wechsler Memory Score $(r=-0.41, P=.002)$ and the number of Short Category Test errors $(r=0.32$, $P=.012$ ), again indicating that cognitive abilities are affected by atrophy.

The last 4 rows of Table 10 show correlation between changes in brain MRI findings from early baseline to late follow-up with neuropsychological testing at late followup. The change in brain atrophy from baseline to followup was not associated with any neuropsychological test findings in this limited patient sample.

Of note is the finding that the surgical groups did not differ with respect to measures of CSF volumes, which serve as a more quantitative measure of cerebral atrophy. Moreover, the 2 different measures of cerebral atrophy used in the present study (ie, ordinal scale estimates and quantitative CSF assessment) correlated highly with each other and correlated similarly with neuropsychological outcomes. There were

TABLE 6. Neuropsychological findings among patients with diabetes

\begin{tabular}{|c|c|c|c|c|}
\hline Domain & Variable & CPB $(n=17)$ & OPCAB $(n=10)$ & $P$ value \\
\hline Attention & Digit Span Forward & $6.12(1.32)$ & $6.90(1.29)$ & .15 \\
\hline Attention & Digit Span Backward & $4.41(1.33)$ & $4.90(1.73)$ & .42 \\
\hline Attention & Spatial Span Forward & $5.06(0.97)$ & $5.10(1.45)$ & .93 \\
\hline Attention & Spatial Span Backward & $4.18(1.13)$ & $5.00(0.94)$ & .06 \\
\hline Memory & RAVLT Trial 5 & $8.41(2.24)$ & $10.2(2.82)$ & .08 \\
\hline Memory & RAVLT Delayed Recall & $6.12(2.42)$ & $7.40(3.53)$ & .27 \\
\hline Memory & BVMT-R Trial 3 & $6.24(3.21)$ & $7.2(3.55)$ & .48 \\
\hline Memory & BVMT Delayed Recall & $5.82(3.28)$ & $6.10(3.41)$ & .84 \\
\hline Executive/Intellectual & WASI Full-Scale IQ & $94.8(16.5)$ & $104.7(20.2)$ & .18 \\
\hline Executive/Intellectual & WASI Vocabulary IQ & $9.41(3.47)$ & $10.6(3.92)$ & .42 \\
\hline Executive/Intellectual & WASI Matrix IQ & $8.53(4.14)$ & $10.8(3.94)$ & .17 \\
\hline Executive/Intellectual & Short Category Test Errors & $46.5(10.7)$ & $37.1(15.3)$ & .07 \\
\hline Mood & Beck Depression Inventory & $6.6(4.1)$ & $9.1(11.5)$ & .52 \\
\hline
\end{tabular}

Data are presented as means (standard deviations). $C P B$, Cardiopulmonary bypass; $O P C A B$, off-pump coronary artery bypass; RAVLT, Rey Auditory Verbal Learning Test; $B V M T-R$, Brief Visuospatial Memory Test-Revised; WASI, Wechsler Abbreviated Scale of Intelligence. 
TABLE 7. Results of brain MRI studies scored on ordinal scales

\begin{tabular}{|c|c|c|c|c|c|c|c|c|c|}
\hline \multirow[b]{2}{*}{ Variable } & \multicolumn{3}{|c|}{ Early postoperative brain MRI } & \multicolumn{3}{|c|}{ MRI at late follow-up } & \multicolumn{3}{|c|}{ Change: Follow-up-baseline } \\
\hline & $\begin{array}{c}\text { CPB } \\
(\mathbf{n}=\mathbf{8 5}) \\
\end{array}$ & $\begin{array}{r}\text { OPCAB } \\
(\mathbf{n}=\mathbf{8 3}) \\
\end{array}$ & $\begin{array}{c}\text { Wilcoxon } \\
P \text { value }\end{array}$ & $\begin{array}{c}\text { CPB } \\
(\mathbf{n}=\mathbf{3 5}) \\
\end{array}$ & $\begin{array}{l}\text { OPCAB } \\
(\mathbf{n}=32) \\
\end{array}$ & $\begin{array}{c}\text { Wilcoxon } \\
P \text { value } \\
\end{array}$ & $\begin{array}{c}\text { CPB } \\
(\mathbf{n}=27) \\
\end{array}$ & $\begin{array}{l}\text { OPCAB } \\
(\mathbf{n}=\mathbf{3 2}) \\
\end{array}$ & $\begin{array}{c}\text { Wilcoxon } \\
P \text { value } \\
\end{array}$ \\
\hline DWI & 0.73 & 0.88 & .37 & 0.09 & 0.00 & .36 & -0.84 & -0.67 & .59 \\
\hline $\mathrm{T} 2$ & 1.93 & 2.22 & .38 & 3.49 & 3.88 & .23 & 1.88 & 1.85 & .93 \\
\hline Temporal atrophy & 0.54 & 0.49 & .36 & 0.89 & 0.97 & .87 & 0.59 & 0.48 & .64 \\
\hline Frontal atrophy & 0.41 & 0.59 & .09 & 0.91 & 0.72 & .29 & 0.53 & 0.44 & .56 \\
\hline $\begin{array}{l}\text { Perivent } \\
\text { frontal }\end{array}$ & - & - & - & 1.30 & 1.38 & .70 & - & - & - \\
\hline $\begin{array}{l}\text { Perivent } \\
\text { posterior }\end{array}$ & - & - & - & 1.29 & 1.71 & .13 & - & - & - \\
\hline $\begin{array}{l}\text { Perivent } \\
\text { lateral }\end{array}$ & - & - & - & 1.06 & 1.19 & .51 & - & - & - \\
\hline
\end{tabular}

All numeric values are means of ordinal scales within each surgical group. $M R I$, Magnetic resonance imaging; $C P B$, cardiopulmonary bypass; $O P C A B$, off-pump coronary artery bypass; $D W I$, diffusion-weighted abnormalities in subcortical white matter; $T 2$, T2-weighted or fluid attenuated inversion recovery signal abnormalities in subcortical white matter; Temporal atrophy, atrophic changes in temporal lobe (subjective ordinal scale); Frontal atrophy, atrophic changes in frontal lobe (subjective ordinal scale); Perivent frontal, thickness of lesions present in the periventricular white matter adjacent to the frontal horns; Perivent posterior, thickness of lesions present in the periventricular white matter adjacent to the posterior trigones; Periventricular lateral, thickness of lesions present in the periventricular white matter adjacent to the midlateral portion of the ventricles.

several correlations between CSF volumes and neuropsychological tests of moderate strength. Significant correlations were found between the Spatial Span Backwards score and frontal periventricular volume $(r=-0.29$, $P=.017)$ and peritrigonal volume $(r=-0.30, P=.013)$. Also, significant associations exist between the RAVLT-5 score and frontal periventricular volume $(r=-0.25$, $P=.042)$, anterolateral temporal volume $(r=-0.30$, $P=.012)$, medial temporal volumes $(r=-0.35$, $P=.004)$, and peritrigonal volume $(r=-0.29, P=.018)$. No significant correlations were detected between the Short Category Test Errors and any CSF region (Table 11).

\section{DISCUSSION}

The present prospective randomized trial is the largest US trial of OPCAB with angiographic graft assessment and longer-term follow-up of neuroanatomic and neuropsy- chological outcomes. Survivors voluntarily returned at a mean of 7.5 years for formal neuropsychological testing and brain MRI. Of 200 patients initially randomized, 76 (41 undergoing CPB and 35 undergoing OPCAB) had neuropsychological testing at late follow-up. Groups were similar with respect to potential confounders, such as age, sex, depression, and IQ, both at enrollment and at long-term follow-up.

At late follow-up, patients undergoing OPCAB showed better attention, performing better at simultaneously tracking and mentally manipulating visual information $(P=.011)$. Patients undergoing OPCAB showed a trend toward better verbal learning $(P=.064)$. There were no significant differences between groups in visuospatial memory. Patients undergoing $\mathrm{OPCAB}$ showed better cognitive reasoning, making fewer errors in reasoning $(P=.05)$. There were no domains in which patients undergoing CPB outperformed

TABLE 8. Results of brain MRI studies scored on ordinal scales by diabetes status

\begin{tabular}{|c|c|c|c|c|c|c|c|c|c|}
\hline \multirow[b]{2}{*}{ Variable } & \multicolumn{3}{|c|}{ Early postoperative brain MRI } & \multicolumn{3}{|c|}{ MRI at late follow-up } & \multicolumn{3}{|c|}{ Change: Follow-up-baseline } \\
\hline & $\begin{array}{c}\text { Diabetes, } \\
\text { no }(\mathbf{n}=\mathbf{1 1 0})\end{array}$ & $\begin{array}{c}\text { Diabetes, } \\
\text { yes }(n=58)\end{array}$ & $\begin{array}{c}\text { Wilcoxon } \\
P \text { value }\end{array}$ & $\begin{array}{c}\text { Diabetes, } \\
\text { no }(n=46)\end{array}$ & $\begin{array}{c}\text { Diabetes, } \\
\text { yes }(n=21)\end{array}$ & $\begin{array}{c}\text { Wilcoxon } \\
P \text { value }\end{array}$ & $\begin{array}{l}\text { Diabetes, } \\
\text { no }(n=41)\end{array}$ & $\begin{array}{c}\text { Diabetes, } \\
\text { yes }(n=18)\end{array}$ & $\begin{array}{c}\text { Wilcoxon } \\
P \text { value }\end{array}$ \\
\hline DWI & 0.55 & 1.29 & .009 & 0.0 & 0.14 & .15 & -0.73 & -0.83 & .98 \\
\hline $\mathrm{T} 2$ & 1.94 & 2.33 & .21 & 3.5 & 4.05 & .29 & 2.02 & 1.50 & .27 \\
\hline Frontal atrophy & 0.48 & 0.51 & .74 & 0.80 & 0.86 & .80 & 0.51 & 0.44 & .67 \\
\hline Temporal atrophy & 0.51 & 0.53 & .95 & 0.78 & 1.24 & .059 & 0.29 & 1.11 & .004 \\
\hline $\begin{array}{l}\text { Perivent } \\
\text { frontal }\end{array}$ & - & - & - & 1.39 & 1.24 & .34 & - & - & - \\
\hline $\begin{array}{l}\text { Perivent } \\
\text { posterior }\end{array}$ & - & - & - & 1.49 & 1.52 & .98 & - & - & - \\
\hline Perivent & - & - & - & 1.02 & 1.33 & .13 & - & - & - \\
\hline
\end{tabular}

All numeric values are means of ordinal scales within each surgical group. MRI, Magnetic resonance imaging; DWI, diffusion-weighted abnormalities in subcortical white matter; T2, T2-weighted or fluid attenuated inversion recovery signal abnormalities in subcortical white matter; Frontal atrophy, atrophic changes in frontal lobe (subjective ordinal scale); Temporal atrophy, atrophic changes in temporal lobe (subjective ordinal scale); Perivent frontal, thickness of lesions present in the periventricular white matter adjacent to the frontal horns; Perivent posterior, thickness of lesions present in the periventricular white matter adjacent to the posterior trigones; Perivent lateral, thickness of lesions present in the periventricular white matter adjacent to the mid-lateral portion of the ventricles. 
TABLE 9. Results of brain MRI studies among patients with diabetes

\begin{tabular}{|c|c|c|c|c|c|c|c|c|c|}
\hline \multirow[b]{2}{*}{ Variable } & \multicolumn{3}{|c|}{ Early postoperative brain MRI } & \multicolumn{3}{|c|}{ MRI at late follow-up } & \multicolumn{3}{|c|}{ Change: Follow-up-baseline } \\
\hline & $\begin{array}{c}\text { CPB } \\
(n=29) \\
\end{array}$ & $\begin{array}{l}\text { OPCAB } \\
(n=29) \\
\end{array}$ & $\begin{array}{c}\text { Wilcoxon } \\
P \text { value } \\
\end{array}$ & $\begin{array}{c}\text { CPB } \\
(n=11)\end{array}$ & $\begin{array}{c}\text { OPCAB } \\
(\mathbf{n}=7) \\
\end{array}$ & $\begin{array}{c}\text { Wilcoxon } \\
P \text { value } \\
\end{array}$ & $\begin{array}{c}\text { CPB } \\
(n=11)\end{array}$ & $\begin{array}{c}\text { OPCAB } \\
(\mathbf{n}=7) \\
\end{array}$ & $\begin{array}{c}\text { Wilcoxon } \\
P \text { value } \\
\end{array}$ \\
\hline DWI & 1.14 & 1.45 & .68 & 0.27 & 0.00 & .50 & -0.36 & -1.57 & .31 \\
\hline $\mathrm{T} 2$ & 2.14 & 2.52 & .58 & 4.36 & 4.14 & .88 & 1.73 & 1.14 & .44 \\
\hline Atrophy & 0.41 & 0.55 & .25 & 1.00 & 0.71 & .48 & 0.55 & 0.29 & .48 \\
\hline TT & 0.55 & 0.52 & .53 & 1.18 & 1.71 & .26 & 0.82 & 1.57 & .17 \\
\hline
\end{tabular}

$M R I$, Magnetic resonance imaging; $C P B$, cardiopulmonary bypass; $O P C A B$, off-pump coronary artery bypass; $D W I$, diffusion-weighted abnormalities in subcortical white matter; $T 2$, T2-weighted or fluid attenuated inversion recovery signal abnormalities in subcortical white matter; $T T$, temporal tip atrophy.

those undergoing $\mathrm{OPCAB}$. These results overall suggest that patients undergoing OPCAB had better preserved executive function. However, these differences were relatively small, in the range of $12 \%$ to $15 \%$, and none met the benchmark of a $20 \%$ difference, which is frequently considered in the literature to be clinically significant. ${ }^{27,34}$

A strong relative benefit of off-pump techniques over conventional $\mathrm{CABG}$ during $\mathrm{CPB}$ with respect to neurocognitive outcomes has been reported in several single-center prospective trials. Among 40 randomized patients, Diegeler and associates ${ }^{35}$ reported that emboli detected in the middle cerebral artery during $\mathrm{OPCAB}$ were fewer than during conventional $\mathrm{CABG}$; postoperative serum levels of the neurobiochemical marker protein S-100 were correspondingly lower and neurocognitive function better in patients randomized to OPCAB than to conventional CABG during CPB. Zamvar and colleagues ${ }^{36}$ randomized 60 patients and reported neurocognitive impairment at 1 week postoperatively in $27 \%$ of patients undergoing OPCAB and $63 \%$ of patients undergoing $\mathrm{CPB}$; at 10 weeks postoperatively, $10 \%$ of patients undergoing OPCAB and $40 \%$ of patients undergoing $\mathrm{CPB}$ showed impairment during neurocognitive testing.

Van Dijk and coworkers ${ }^{37}$ randomized 281 patients to OPCAB versus $C P B$ and reported improved cognitive out- comes 3 months after the procedure, but these effects were small and became negligible at 12 months. Al-Ruzzeh and associates ${ }^{38}$ randomized 168 patients and found those who underwent OPCAB showed better neurocognitive function at 6 weeks and 6 months postoperatively compared with those who underwent CABG during CPB.

However, the subset of 120 randomized patients in the Best Bypass Surgery trial who had neuropsychological testing preoperatively and postoperatively did not demonstrate any significant difference in the incidence of cognitive dysfunction 3 months after either OPCAB or CPB ${ }^{39}$ Similarly, 201 patients randomized by Hernandez and colleagues ${ }^{40}$ to have OPCAB versus $C P B$ demonstrated no significant difference in the incidence of neurocognitive deficits 6 months after surgical intervention. Lund and coworkers ${ }^{41}$ reported a large, statistically significant difference between OPCAB and CPB in cerebral microemboli detected by means of transcranial Doppler ultrasonographic analysis among 120 randomized patients but no significant difference in neuropsychological performance between groups nor any correlation between the number of cerebral microemboli and the degree of neurocognitive dysfunction. Similarly, Liu and associates ${ }^{42}$ compared intraoperative cerebral microemboli and neuropsychological function between matched cohorts undergoing $\mathrm{OPCAB}$ versus $\mathrm{CPB}$ and found that

TABLE 10. Spearman rank correlations between selected NP tests and MRI findings

\begin{tabular}{|c|c|c|c|c|}
\hline MRI finding & Time period & $\begin{array}{c}\text { Wechsler } \\
\text { Memory Score }\end{array}$ & $\begin{array}{c}\text { Rey Auditory Verbal } \\
\text { Learning Test }\end{array}$ & $\begin{array}{c}\text { Short Category } \\
\text { Test Errors }\end{array}$ \\
\hline DWI & Baseline & $-0.16(P=.23)$ & $-0.16(P=.22)$ & $0.13(P=.33)$ \\
\hline $\mathrm{T} 2$ & Baseline & $-0.13(P=.31)$ & $-0.16(P=.23)$ & $0.20(P=.14)$ \\
\hline Frontal atrophy & Baseline & $-0.29(P=.024)$ & $-0.03(P=.85)$ & $0.18(P=.17)$ \\
\hline Temporal tip atrophy & Baseline & $-0.05(P=.72)$ & $0.04(P=.78)$ & $0.26(P=.046$ \\
\hline DWI & Follow-up & $-0.09(P=.50)$ & $-0.14(P=.30)$ & $0.04(P=.75)$ \\
\hline $\mathrm{T} 2$ & Follow-up & $-0.07(P=.62)$ & $-0.14(P=.29)$ & $0.07(P=.59)$ \\
\hline Frontal atrophy & Follow-up & $-0.41(P=.002)$ & $-0.10(P=.44)$ & $0.32(P=.012$ \\
\hline Temporal tip atrophy & Follow-up & $-0.27(P=.041)$ & $-0.30(P=.021)$ & $0.19(P=.14)$ \\
\hline DWI & Change & $0.14(P=.30)$ & $0.13(P=.32)$ & $-0.13(P=.32)$ \\
\hline $\mathrm{T} 2$ & Change & $0.09(P=.50)$ & $-0.002(P=.98)$ & $-0.22(P=.10)$ \\
\hline Frontal atrophy & Change & $-0.23(P=.07)$ & $-0.12(P=.35)$ & $0.23(P=.09)$ \\
\hline Temporal tip atrophy & Change & $-0.17(P=.19)$ & $-0.25(P=.052)$ & $0.008(P=.95)$ \\
\hline
\end{tabular}

$N P$, Neuropsychological; $M R I$, magnetic resonance imaging; $D W I$, diffusion-weighted abnormalities in subcortical white matter; T2, T2-weighted or fluid attenuated inversion recovery signal abnormalities in subcortical white matter; Frontal atrophy, atrophic changes in frontal lobe (subjective ordinal scale); Temporal atrophy, atrophic changes in temporal lobe (subjective ordinal scale). 
TABLE 11. Spearman rank correlation coefficients between selected NP tests and CSF volumes at late follow-up

\begin{tabular}{llrr}
\hline \multicolumn{1}{c}{ CSF region } & $\begin{array}{c}\text { Wechsler } \\
\text { Memory Score }\end{array}$ & $\begin{array}{c}\text { Rey Auditory Verbal } \\
\text { Learning Test }\end{array}$ & $\begin{array}{c}\text { Short Category } \\
\text { Test Errors }\end{array}$ \\
\hline Anterior frontal lobes & $-0.06(P=.61)$ & $-0.10(P=.40)$ & $-0.04(P=.75)$ \\
Frontal periventricular & $-0.29(P=.017)$ & $-0.25(P=.042)$ & $0.05(P=.70)$ \\
Anterolateral temporal & $-0.14(P=.25)$ & $-0.30(P=.012)$ & $-0.06(P=.64)$ \\
Medial temporal & $-0.13(P=.28)$ & $-0.35(P=.004)$ & $-0.02(P=.90)$ \\
Perisylvian & $-0.14(P=.26)$ & $-0.15(P=.23)$ & $-0.03(P=.79)$ \\
Peritrigonal & $-0.30(P=.013)$ & $-0.29(P=.018)$ & $0.03(P=.82)$ \\
\hline
\end{tabular}

$N P$, Neuropsychological; $C S F$, cerebrospinal fluid.

OPCAB was associated with significantly fewer cerebral microemboli, but similar incidence of neuropsychological dysfunction.

The finding in the present study that neuropsychological function was superior in patients who have had OPCAB versus conventional CABG during $\mathrm{CPB}$ is consistent with some previous reports ${ }^{12,35,36}$ but inconsistent with others. ${ }^{40-42}$ The relatively small sample size and absence of baseline preoperative neuropsychological testing in the present study render these findings additive to the literature rather than conclusive or definitive.

Before discharge from the index surgical hospitalization, diffusion-weighted brain MRI in 168 patients showed no significant differences between groups in atrophy, subcortical white matter lesions, or acute infarctions. Among 59 patients who had brain MRI both at the index hospitalization and at a mean of 7.5 years of follow-up, there were no significant differences between groups with respect to atrophy over time or new subcortical white matter lesions or infarctions. These findings are consistent with those of Lund and colleagues, ${ }^{29}$ who reported a similar incidence of new postoperative cerebral lesions in 120 patients randomized to OPCAB versus $\mathrm{CPB}$ imaged with brain MRI at 3 months postoperatively.

The present study includes 168 diffusion brain MRI studies early after randomization to OPCAB versus $C A B G$ during CPB. This is the largest such dataset extant and, as such, has the opportunity to add meaningfully to our understanding of the effect of CPB on neuroanatomic outcomes in patients undergoing surgical coronary revascularization. Of primary interest is the fact that very few patients had any new cerebral infarctions detectable by means of brain MRI after coronary bypass either with or without CPB. This reflects a paucity of emboli of sufficient size to be detectable by means of currently available MRI imaging. Nonetheless, if the neuropsychological differences observed between surgical groups in the present study and in several previous studies are the result of fewer embolic events after OPCAB than after $\mathrm{CABG}$ during $\mathrm{CPB}$, then one must assume that neurocognitive decline might be caused by emboli too small to be detected by means of MRI scanning. Alternatively, there might be other ways in which CPB impairs postoperative cerebral function. Such putative mechanisms might include the systemic inflammatory response, hemodilution, hypothermia, and nonspecific metabolic derangements. Such nonembolic cerebral impairment might be expected to resolve over a period of weeks or months. Indeed, several studies have reported a neurocognitive benefit of OPCAB over CPB early after surgical intervention but no difference at 6 to 12 months. ${ }^{43,44}$ Although diffusion-weighted brain MRI can distinguish between recent cerebral infarctions (around which localized edema is evident) and old cerebral infarctions (which lack edema) but has poor resolution to detect very small emboli and does not image metabolic dysfunction, which might exist after microembolic injury in the absence of detectible cerebral infarction.

More rapid progression of brain atrophy and cognitive decline in nonsurgical patients with diabetes mellitus compared with nondiabetic patients has been previously reported. ${ }^{45}$ Moreover, white matter changes predict cognitive decline in elderly nonsurgical patients. ${ }^{46}$ The finding in the present study that diabetic patients had significantly more acute perioperative cerebral infarctions by means of brain MRI than nondiabetic patients and worse atrophy at late follow-up after CABG has not been previously reported. It is possible that diabetic vasculopathy in both extracranial and intracerebral vessels predisposes diabetic patients to greater risk of macroemboli and microemboli during cardiac surgery, irrespective of the use or avoidance of CPB. Moreover, the absence of any difference in infarctions or atrophy between surgical treatment groups among diabetic patients might reflect the use of an aortic clamp in both groups. Interestingly, the association of cognitive impairment with brain MRI measures has been equivocal in nonsurgical patient populations as well. ${ }^{47}$

\section{Limitations}

The present study has several important limitations, including a small sample size. Despite the absence of any significant difference in the means of the clinical characteristics of the randomized patient groups at baseline, at late follow-up, or within surgical groups compared between baseline and follow-up, the large attrition between enrollment and late follow-up introduces the potential for important selection bias for which no adjustment is possible. The 
absence of neuropsychological testing before surgical intervention or at early follow-up limits the strength of comparisons between groups over time.

\section{CONCLUSIONS}

After a mean of 7.5 years of follow-up in this randomized trial, OPCAB was associated with better performance in some neuropsychological domains compared with $\mathrm{CPB}$, primarily on tests of executive function. These differences are of uncertain clinical significance. Early diffusionweighted brain MRI showed no significant differences in acute cerebral infarctions between the OPCAB and $\mathrm{CPB}$ groups but more frequent lesions among diabetic patients in both groups. Temporal and frontal lobe cerebral atrophy demonstrated by early or late MRI scanning correlated with impaired neuropsychological function in both groups. However, repeat MRI at late follow-up showed interval atrophic changes that were worse in patients with diabetes but similar between surgical groups.

\section{References}

1. Buffolo E, de Andrade JCS, Branco JNR, Teles CA, Aguiar LF, Gomes WJ. Coronary artery bypass grafting without cardiopulmonary bypass. Ann Thorac Surg. 1996;61:63-6.

2. Puskas JD, Wright CE, Ronson RS, Brown WM 3rd, Gott JP, Guyton RA. Offpump multivessel coronary bypass via sternotomy is safe and effective. Ann Thorac Surg. 1998;66:1068-72.

3. Cartier R, Brann S, Dagenais F, Martineau R, Couturier A. Systematic off-pump coronary artery revascularization in multivessel disease: experience of three hundred cases. J Thorac Cardiovasc Surg. 2000;119:221-9.

4. Czerny M, Baumer H, Kilo J, Zuckermann A, Grubhofer G, Chevtchik O, et al. Complete revascularization in coronary artery bypass grafting with and without cardiopulmonary bypass. Ann Thorac Surg. 2001;71:165-9.

5. Cleveland JC Jr, Shroyer AL, Chen AY, Peterson E, Grover FL. Off-pump coronary artery bypass grafting decreases risk-adjusted mortality and morbidity. Ann Thorac Surg. 2001;72:1282-9.

6. Plomondon ME, Cleveland JC Jr, Ludwig ST, Grunwald GK, Kiefe CI, Grover FL, et al. Off-pump coronary artery bypass is associated with improved risk-adjusted outcomes. Ann Thorac Surg. 2001;72:114-9.

7. The Society of Thoracic Surgeons. Fall 2009 Report. Adult cardiac database executive summary. Available at: http://www.sts.org/sections/stsnationaldatabase/ publications/executive/article.html. Accessed January 24, 2009

8. van Dijk D, Nierich AP, Jansen EW, Nathoe HM, Suyker WJ, Diephuis JC, et al. Early outcome after off-pump versus on-pump coronary bypass surgery: results from a randomized study. Circulation. 2001;104:1761-6.

9. Angelini GD, Taylor FC, Reeves BC, Ascione R. Early and midterm outcome after off-pump and on-pump surgery in Beating Heart Against Cardioplegic Arrest Studies (BHACAS 1 and 2): a pooled analysis of two randomised controlled trials. Lancet. 2002;359:1194-9.

10. Newman MF, Grocott HP, Mathew JP, White WD, Landolfo K, Reves JG, et al. Report of the substudy assessing the impact of neurocognitive function on quality of life 5 years after cardiac surgery. Stroke. 2001;32:2874-81.

11. Nathoe HM, van Dijk D, Jansen EW, Suyker WJ, Diephuis JC, van Boven WJ, et al. A comparison of on-pump and off-pump coronary bypass surgery in lowrisk patients. N Engl J Med. 2003;348:394-402.

12. Lee JD, Lee SJ, Tsushima WT, Yamauchi H, Lau WT, Popper J, et al. Benefits of off-pump bypass on neurologic and clinical morbidity: a prospective randomized trial. Ann Thorac Surg. 2003;76:18-26.

13. Puskas JD, Williams WH, Duke PG, Staples JR, Glas KE, Marshall JJ, et al. Offpump coronary artery bypass grafting provides complete revascularization with reduced myocardial injury, transfusion requirements, and length of stay: a prospective randomized comparison of two hundred unselected patients undergoing off-pump versus conventional coronary artery bypass grafting. J Thorac Cardiovasc Surg. 2003;125:797-808.
14. Cheng DC, Bainbridge D, Martin JE, Novick RJ. Does off-pump coronary artery bypass reduce mortality, morbidity, and resource utilization when compared with conventional coronary artery bypass? A meta-analysis of randomized trials. Anesthesiology. 2005;102:188-203.

15. Sellke FW, DiMaio JM, Caplan LR, Ferguson TB, Gardner TJ, Hiratzka LF, et al. Comparing on-pump and off-pump coronary artery bypass grafting: numerous studies but few conclusions: a scientific statement from the American Heart Association council on cardiovascular surgery and anesthesia in collaboration with the interdisciplinary working group on quality of care and outcomes research. Circulation. 2005;111:2858-64.

16. Puskas JD, Edwards FH, Pappas PA, O’Brien S, Peterson ED, Kilgo P, et al. Offpump techniques benefit men and women and narrow the disparity in mortality after coronary bypass grafting. Ann Thorac Surg. 2007;84:1447-54.

17. Hannan EL, Wu C, Smith CR, Higgins RS, Carlson RE, Culliford AT, et al. Offpump versus on-pump coronary artery bypass graft surgery: differences in shortterm outcomes and in long-term mortality and need for subsequent revascularization. Circulation. 2007;116:1145-52.

18. Murkin JM, Boyd WD, Ganapathy S, Adams SJ, Peterson RC. Beating heart surgery: why expect less central nervous system morbidity? Ann Thorac Surg. 1999; 68:1498-501.

19. Hammon JW, Stump DA, Butterworth JF, Moody DM, Rorie K, Deal DD, et al. Single crossclamp improves 6-month cognitive outcome in high-risk coronary bypass patients: the effect of reduced aortic manipulation. J Thorac Cardiovasc Surg. 2006;131:114-21.

20. Newman MF, Kirchner JL, Phillips-Bute B, Gaver V, Grocott H, Jones RH, et al Longitudinal assessment of neurocognitive function after coronary-artery bypass surgery. N Engl J Med. 2001;344:395-402.

21. Kilo J, Czerny M, Gorlitzer M, Zimpfer D, Baumer H, Wolner E, et al. Cardiopulmonary bypass affects cognitive brain function after coronary artery bypass grafting. Ann Thorac Surg. 2001;72:1926-32.

22. Collie A, Darby DG, Falleti MG, Silbert BS, Maruff P. Determining the extent of cognitive change after coronary surgery: a review of statistical procedures. Ann Thorac Surg. 2002;73:2005-11.

23. Selnes OA, Grega MA, Bailey MM, Pham LD, Zeger SL, Baumgartner WA, et al Cognition 6 years after surgical or medical therapy for coronary artery disease. Ann Neurol. 2008;63:581-90.

24. Wahrborg P, Booth JE, Clayton T, Nugara F, Pepper J, Weintraub WS, et al. Neuropsychological outcome after percutaneous coronary intervention or coronary artery bypass grafting: results from the Stent or Surgery (SoS) Trial. Circulation. 2004;110:3411-7.

25. Selnes OA, Grega MA, Bailey MM, Pham LD, Zeger SL, Baumgartner WA, et al Do management strategies for coronary artery disease influence 6-year cognitive outcomes? Ann Thorac Surg. 2009;88:445-54

26. Stump DA. Selection and clinical significance of neuropsychologic tests. Ann Thorac Surg. 1995;59:1340-4.

27. Murkin JM, Newman SP, Stump DA, Blumenthal JA. Statement of consensus on assessment of neurobehavioral outcomes after cardiac surgery. Ann Thorac Surg. 1995;59:1289-95.

28. Jacobson NS, Truax P. Clinical significance: a statistical approach to defining meaningful change in psychotherapy research. J Consult Clin Psychol. 1991; 59:12-9.

29. Lund C, Sundet K, Tennoe B, Hol PK, Rein KA, Fosse E, et al. Cerebral ischemic injury and cognitive impairment after off-pump and on-pump coronary artery bypass grafting surgery. Ann Thorac Surg. 2005;80:2126-31.

30. Puskas JD, Williams WH, Mahoney EM, Huber PR, Block PC, Duke PG, et al Off-pump vs conventional coronary artery bypass grafting: early and 1-year graft patency, cost, and quality-of-life outcomes: a randomized trial. JAMA. 2004;291: 1841-9.

31. Puskas J, Williams W, O'Donnell R, Patterson R, Sigman S, Smith A, et al Off-pump and on-pump coronary artery bypass are associated with similar graft patency, myocardial ischemia, and freedom form reintervention: Long-term follow-up of a randomized trial. Ann Thorac Surg. In press.

32. Scheltens P, Barkhof F, Leys D, Pruvo JP, Nauta JJP, Vermersch P, et al. A semiquantitative reating scale for the assessment of signal hyperintensities on magnetic resonance imaging. J Neurol Sci. 1993;114:7-12.

33. Arimura H, Yoshiura T, Kumazawa S, Tanaka K, Koga H, Mihara F, et al. Automated method for identification of patients with Alzheimer's disease based on three-dimensional MR images. Acad Radiol. 2008;15:274-84.

34. Marasco SF, Sharwood LN, Abramson MJ. No improvement in neurocognitive outcomes after off-pump versus on-pump coronary revascularisation: a metaanalysis. Eur J Cardiothorac Surg. 2008;33:961-70. 
35. Diegeler A, Hirsch R, Schneider F, Schilling LO, Falk V, Rauch T, et al. Neuromonitoring and neurocognitive outcome in off-pump versus conventional coronary bypass operation. Ann Thorac Surg. 2000;69:1162-6.

36. Zamvar V, Williams D, Hall J, Payne N, Cann C, Young K, et al. Assessment of neurocognitive impairment after off-pump and on-pump techniques for coronary artery bypass graft surgery: prospective randomised controlled trial. BMJ. 2002; 325:1268.

37. Van Dijk D, Jansen EW, Hijman R, Nierich AP, Diephuis JC, Moons KG, et al. Cognitive outcome after off-pump and on-pump coronary artery bypass graft surgery: a randomized trial. JAMA. 2002;287:1405-12.

38. Al-Ruzzeh S, George S, Bustami M, Wray J, Ilsley C, Athanasiou T, et al. Effect of off-pump coronary artery bypass surgery on clinical, angiographic, neurocognitive, and quality of life outcomes: randomised controlled trial. BMJ. 2006;332:1365.

39. Jensen BO, Hughes P, Rasmussen LS, Pedersen PU, Steinbruchel DA. Cognitive outcomes in elderly high-risk patients after off-pump versus conventional coronary artery bypass grafting: a randomized trial. Circulation. 2006;113:2790-5.

40. Hernandez F Jr, Brown JR, Likosky DS, Clough RA, Hess AL, Roth RM, et al Neurocognitive outcomes of off-pump versus on-pump coronary artery bypass: a prospective randomized controlled trial. Ann Thorac Surg. 2007;84:1897-903.

41. Lund C, Hol PK, Lundblad R, Fosse E, Sundet K, Tennoe B, et al. Comparison of cerebral embolization during off-pump and on-pump coronary artery bypass surgery. Ann Thorac Surg. 2003;76:765-70.

42. Liu YH, Wang DX, Li LH, Wu XM, Shan GJ, Su Y, et al. The effects of cardiopulmonary bypass on the number of cerebral microemboli and the incidence of cognitive dysfunction after coronary artery bypass graft surgery. Anesth Analg. 2009;109:1013-22

43. Motallebzadeh R, Bland JM, Markus HS, Kaski JC, Jahangiri M. Neurocognitive function and cerebral emboli: randomized study of on-pump versus off-pump coronary artery bypass surgery. Ann Thorac Surg. 2007;83:475-82.

44. Puskas J, Cheng D, Knight J, Angelini G, DeCannier D, Diegeler A, et al. Offpump versus conventional coronary artery bypass grafting: a meta-analysis and consensus statement from The 2004 ISMICS Consensus Conference. Innovations. 2005;1:3-27.

45. van Elderen SGC, de Roos A, de Craen AJM, Westendorp RGJ, Blauw GJ, Jukema JW, et al. Progression of brain atrophy and cognitive decline in diabetes mellitus. A 3-year follow-up. Neurology. 2010;75:997-1002.

46. Verdelho A, Madureira S, Moleiro C, Ferro JM, Santos CO, Erkinjun T, et al. White matter changes and diabetes predict cognitive decline in the elderly. Neurology. 2010;75:160-7.

47. van Harten B, Ooosterman J, Muslimovic D, van Loon B-J P, Scheltens P, Weinstein HC. Cognitive impairment and MRI correlates in the elderly patients with type 2 diabetes mellitus. Age Ageing. 2007;36:164-70.

\section{Discussion}

Dr John W. Hammon, Jr (Winston-Salem, NC). Thank you very much. John, that was an excellent presentation, as usual, and what we have come to expect from you. I personally admire your tenacity in following your early hypothesis that off-pump surgical intervention was superior to on-pump surgical intervention and your attempts to show us why. I think we all appreciate that there are some definite advantages of off-pump surgical intervention. Let's talk about the secondary end points that you reported today.

I think you are particularly to be congratulated on having the largest series of brain MRI studies done early postoperatively in these 2 groups of patients, and I think your disappointment in finding that there are no differences needs to be discussed a little bit further. Therefore my first question is this: If you took high-risk groups of patients for brain infarction after surgical intervention (ie, patients who had previous stroke or perhaps diabetes) and teased those out, did you find any differences in those groups of patients?

Dr Puskas. We did look at nondiabetic versus diabetic patients and found no significant difference between off-pump and on-pump surgical intervention in either nondiabetic or diabetic patients.

Dr Hammon. Did you find any differences in the total group between diabetic and nondiabetic patients?

Dr Puskas. We did not do that specific $P$ value that I can recall.

Dr Hammon. You might want to do that because I would bet that there would be some differences.

The second item of business is neuropsychological studies. You have been very honest and reported the deficiencies in your group, which was small, and the fact that you got statistical significance means something. Therefore what exactly does it mean? By not having a baseline study, it is very difficult to say that the groups were similar. Some of the neuropsychological tests are very significantly affected by the amount of learning that persons have, and I do not remember in reading your abstract or your article that you had entered that variable in the preoperative characteristics. That is something you might want to look at, because particularly in executive function, people who have higher learning do better on those tests.

Nevertheless, it is a very good study and adds immensely to our knowledge of this subject, and I congratulate you.

Dr Puskas. Thank you, Dr Hammon. We did correct for the level of education in our assessment of the neuropsychological outcomes, but undoubtedly, the single greatest deficit of the design of this study, and it is clearly my fault, is that we did not perform preoperative neuropsychological testing 10 years ago or $81 / 2$ years ago now. We actually designed the trial initially to do preoperative neuropsychological testing and early postoperative diffusionweighted brain MRI scanning, but we found that the inability to get a $\mathrm{PhD}$ neuropsychologist to show up at $6 \mathrm{PM}$ the night before the operation was a show stopper. We could not enroll patients. Therefore we decided that we would jettison that to get the trial done, and therefore after about 2 weeks we gave up; probably my characteristic tenacity failed me at that point. We should have done that, but I cannot go back 8 years.

Dr Lawrence H. Cohn (Boston, Mass). John, let me ask you a question. You might have said this and I apologize for not reading your extensive bibliography, but have you shown in the semiacute phase, such as 3 months or 1 year, imaging differences like you tried to show today?

Dr Puskas. The next largest series of brain MRI scans after cardiac surgery was published in 2005 by Lund. He randomized 120 patients to off-pump and on-pump surgical intervention and did a single study, which was a brain MRI, actually a single brain MRI study at 3 months, and he found no difference in diffusionweighted changes at that time or atrophic changes. I think the bottom line is that brain MRI does not have a resolution adequate to detect small emboli or other factors that affect how we think and function cognitively. It is just too blunt a tool.

Dr Hammon. You keep mentioning emboli as the cause of MRI lesions. We have done a number of studies in our laboratory on what causes MRI lesions, and in about half of them, there is no known cause. Therefore I think to refer to them as embolic lesions is probably not correct. I think you need to call them infarcts.

Dr Puskas. Fair enough. I think that is absolutely well taken. That is probably why, John, the several very small studies have failed to demonstrate a correlation between intraoperative, transcranial, Doppler high-intensity transient signals in the middle cerebral artery and subsequent early postoperative, diffusion-weighted 
MRI scans. That in and of itself is a real paradox unless you accept the fundamental notion that not all cerebral infarcts or microinfarcts are caused by emboli.

Dr Juergen Carl Ennker (Lahr, Germany). Congratulations, Dr Puskas, for this very outstanding study, which again underlines the importance of the OPCAB technique, which is absolutely necessary after the ROOBY study. I have a technical question. I would have expected an even larger benefit for patients undergoing OPCAB. My question is this: Did you use a no-touch aortic technique in your patients undergoing OPCAB, such as by using $\mathrm{T}$ grafts?

Dr Puskas. That is a great question. In the year 2000, when we were doing these operations, we did not have the same attention to avoiding the ascending aorta that we do now. Therefore the large majority of patients in both the off-pump and on-pump groups had some form of clamp on the ascending aorta. You know that the Heartstring and other proximal anastomotic devices were not available in 2000, and therefore the vast majority of patients undergoing off-pump surgery had a partial occlusion clamp on the as- cending aorta unless their intraoperative epiaortic ultrasound demonstrated significant ascending aortic atheroma, in which case they had a no-touch technique in both groups.

Dr Carlos A. Mestres (Barcelona, Spain). Dr Puskas, just one last quick thing. Of course you have mentioned the limitations of your work. In your conclusions you said that you found just a "modest" superiority. The point is this: Was this what you expected? Of course, this is not science, but give us your gut feeling.

Dr Puskas. There are several studies in the literature that would argue that a clinically significant difference in neuropsychological outcomes requires a $20 \%$ change or difference in at least $20 \%$ of the domains tested. We had a statistically significant difference in more than $20 \%$ of the domains tested, but none of those differences actually reached an absolute $20 \%$ decrement or difference between the 2 groups. Of course, what is clinically significant matters differently to different patients: manual dexterity matters more to a violinist and cognitive reasoning matters more to a physicist. 